\title{
PNE: PLANO NACIONAL DE EDUCAÇÃO OU CARTA DE INTENÇÃO?
}

\author{
IVAN VALENTE* \\ ROBERTO ROMANO
}

\begin{abstract}
Le PNE (Plan pour l'Éducation Nationale), défiguré par les vetos du président de la République, Fernando Henrique Cardoso, n'est actuellement qu'une charte d'intentions. L'exigence d'un plan pareil, cependant, a été établie dans la Constitution brésilienne de 1988, et résume les aspirations populaires et des professeurs, pour une éducation democratique et responsable dans le Brésil contemporain. La lutte pour l'éducation ne doit reculer devant les vetos du gouvernement mais, au contraire, doit être renforcée dans les années prochaines.
\end{abstract}

RESUMO: $\mathrm{O}$ artigo relata e discute as várias instâncias e etapas que deram vida ao Plano Nacional de Educação, enfim aprovado em 9 de janeiro de 2001 pelo presidente da República, com nove textos. Tecendo uma comparação entre a proposta inicial, elaborada em 1998 por educadores, profissionais da educação, estudantes, pais de alunos, entre outros, nos congressos nacionais de educação, e o texto final aprovado pelo parlamento, os autores mostram como os interesses imediatos do governo, majoritário no Congresso, acabaram desfigurando o projeto originário da sociedade, reduzindo-o a uma carta de intençôes. Com base nesta análise, os autores concluem que a luta por um "verdadeiro" PNE continua na ordem do dia, exigindo a articulação dos movimentos sociais, o conhecimento detalhado da realidade e a disputa global de propostas e projetos.

Palavras-chave: Estado. Governo. Sociedade. Política educacional. Educação pública.

\footnotetext{
* Ivan Valente é deputado federal suplente pelo PT-SP. E-mail: ivalente@uol.com.br

** Roberto Romano é professor titular de Ética e Filosofia Política do Instituto de Filosofia e Ciências Humanas da UNICAMP. E-mail: romanor@uol.com.br
} 


\section{BRAZILIAN PLAN FOR EDUCATION: \\ Plan? OR LETTER OF INTENT?}

ABSTRACT: This paper reports and discusses the various instances and steps that gave life to the Brazilian Plan for Education (Plano Nacional de Educação - PNE), eventually approved, with nine texts, by the president of Brazil, on January 9, 2001. Drawing a comparison between the initial proposal (elaborated in 1998 by educators, education professionals, students, parent teachers associations, among others, in national congresses on education) and the final text approved by the Parliament, the authors show how the immediate interests of the government, majority in Congress, ended up disfiguring the project that stemmed from society, and reduced it to a letter of intent. Based on this analysis, the authors conclude that the fight for a "real" PNE remains a priority, and requires the articulation of the social movements, a detailed knowledge of reality and the global dispute of proposals and projects.

Key words: State. Government. Society. Educational policies. Public education.

\section{Introdução}

$\mathrm{O}$

Plano Nacional de Educação, elaborado segundo a vontade popular, para definir a intervenção plurianual do Poder Público e da sociedade, é antiga exigência de diversos e relevantes segmentos sociais do nosso país. Em 9 de janeiro de 2001, o presidente da República sancionou, com nove vetos, a Lei $\mathrm{n}^{\circ}$ 10.172/ 2001, que aprova o PNE. Doze anos depois de promulgada a Constituição Federal, surge a norma legislativa posta no seu artigo 214 e requerida pela Lei de Diretrizes e Bases da Educação Nacional (LDB).

Essa não foi uma lei originada de um projeto que tivesse trâmite corriqueiro no parlamento federal. Ao contrário, ela surgiu da pressão social produzida pelo "Fórum Nacional em Defesa da Escola Pública". As inúmeras entidades ali presentes forçaram o governo a se mover ao darem entrada, na Câmara dos Deputados, em 10 de fevereiro de 1998, no Plano Nacional de Educação, elaborado coletivamente por educadores, profissionais da educação, estudantes, pais de alunos etc., nos I e II Congressos Nacionais de Educação (CONEDS). O plano, conhecido como PNE da Sociedade Brasileira, consubstanciou-se no Projeto de Lei $\mathrm{n}^{\circ} 4.155 / 98$, encabeçado pelo deputado Ivan Valente e subscrito por mais de 70 parlamentares e todos os líderes dos partidos de oposição da Câmara dos Deputados. 
A inesperada ação da sociedade forçou o governo Fernando Henrique Cardoso - que, como os fatos viriam a demonstrar, apesar da determinação constitucional e da LDB, não se interessava em nenhum PNE - a desengavetar o seu plano e encaminhá-lo em 11/2/ 98 à Câmara, onde tramitaria, de modo sui generis, como anexo ao PNE da Sociedade Brasileira, sob o número 4.173/98.

Todas as contradiçôes mencionadas acima nos inspiram a alinhar um conjunto de elementos comparativos entre a proposta da sociedade e a que foi aprovada no parlamento. Este artigo, esperamos, pode colaborar para um balanço do PNE já em vigor. Tal balanço, a nosso juízo, na perspectiva que vem sendo exercitada nos CONEDs, precisa ser coletivo e comportar um enfoque plural. É preciso assinalar que um plano da magnitude do PNE deve ser assumido pelo Poder Público, especialmente pelo Congresso Nacional, como tarefa de Estado. Ele não pode ser reduzido às "razōes" de governos que agem para conquistar vitórias conjunturais, em proveito de seus interesses imediatos. Como veremos adiante, foi sob este último prisma que, infelizmente, conduziu-se no caso do PNE, no parlamento federal, a maioria conservadora e governista.

PNE da sociedade versus PNE de FHC - dois projetos de Brasil

As duas propostas de PNE materializavam mais do que a existência de dois projetos de escola, ou duas perspectivas opostas de política educacional. Elas traduziam dois projetos conflitantes de país. De um lado, tínhamos o projeto democrático e popular, expresso na proposta da sociedade. De outro, enfrentávamos um plano que expressava a política do capital financeiro internacional e a ideologia das classes dominantes, devidamente refletido nas diretrizes e metas do governo. O PNE da Sociedade Brasileira reivindicava o fortalecimento da escola pública estatal e a plena democratização da gestão educacional, como eixo do esforço para se universalizar a educação básica. Isso implicaria propor objetivos, metas e meios audaciosos, incluindo a ampliação do gasto público total para a manutenção e o desenvolvimento do ensino público. $\mathrm{O}$ custo seria mudar o dispêndio, equivalente a menos de $4 \%$ do PIB nos anos de 1990 , para $10 \%$ do PIB, ao fim dos 10 anos do PNE. A proposta da sociedade retomava, visando a organizar a gestão educacional, o embate histórico pelo efetivo Sistema Nacional de Educação, contraposto e antagônico ao expediente governista do Sistema Nacional de Avaliação. 
O PNE do governo insistia na permanência da atual política educacional e nos seus dois pilares fundamentais: máxima centralização, particularmente na esfera federal, da formulação e da gestão política educacional, com o progressivo abandono, pelo Estado, das tarefas de manter e desenvolver o ensino, transferindo-as, sempre que possível, para a sociedade.

\section{O Relatório Marchezan}

O parlamento viu-se diante de um grave conflito ao elaborar o PNE, num quadro em que o governo contava com ampla maioria na Câmara dos Deputados e no Senado. Era previsível que tal poder fosse mobilizado para controlar a tramitação da matéria. Foi indicado como seu relator, na Comissão de Educação, o falecido deputado Nelson Marchezan (PSDB-RS), o qual subscreveu o relatório (em verdade um substitutivo à proposta da sociedade) que tomou o seu nome. Esse controle se operou abreviando a participação social no debate do Congresso, inclusive fazendo preponderar nas audiências públicas os convites para autoridades e técnicos vinculados às posiçóes oficiais. $\mathrm{O}$ substitutivo (que se tornou o texto-base da lei) tem conteúdo peculiar: ele é um escrito teratológico (espécie de Frankenstein) que simula o diálogo com as teses geradas pela mobilização social (sobretudo no diagnóstico da situação educacional), mas adota a política do Governo FHC nas diretrizes, nos objetivos e nas metas. Estes últimos pontos são o que, de fato, possui relevância estratégica num Plano.

O fundamento da Lei no 10.172/2001 encontra-se na política educacional imposta pelo Banco Mundial ao MEC. O texto assume, como fio condutor, o conhecido e esperto modo de legislar das elites: no que interessa aos "de cima" (no caso, a política do governo) temos uma lei com comandos precisos, num estilo criterioso, detalhista e, regra geral, auto-aplicável. No que interessa aos "de baixo" e que eventualmente não tenha sido possível ou conveniente suprimir, recorre-se à redação "genérica", no mais das vezes, sujeita a uma regulamentação sempre postergada. Vejamos dois exemplos disso numa seção (a do ensino fundamental) em que o governo teria melhores condições para produzir algo em diálogo com a sociedade:

a) Detalhismo, ao se intensificar a centralização da política educacional, como na meta 8: “assegurar que, em três anos, todas as escolas tenham formulado seus projetos pedagógicos, 
com observância das Diretrizes Curriculares para o ensino fundamental e dos Parâmetros Curriculares Nacionais";

b) Generalismo ambíguo na ausência de definição de prazo e meios, ao retardar a sua implementação, como na meta 20: "eliminar a existência, nas escolas, de mais de dois turnos diurnos e um turno noturno, sem prejuízo do atendimento da demanda”.

No que se refere à distância entre o plano e o que o país precisa, pode-se constatar, a partir da definição mesma dos seus próprios objetivos gerais, que o PNE retroage ante o que dispõe a Constituição no seu artigo 214. Diz a Carta: o plano deve visar "à articulação e ao desenvolvimento do ensino em seus diversos níveis e à integração das ações do Poder Público" que conduzam à viabilização. Vejamos alguns diferentes objetivos entre a Carta e o Plano, na tabela a seguir:

Objetivos do PNE na constituição versus Lei aprovada

\begin{tabular}{|l|l|}
\hline DIZ A CONSTITUIÇÃO & DIZ O PNE APROVADO \\
\hline - erradicar o analfabetismo & Neste ponto não faz referência \\
\hline - universalizar o atendimento escolar & - elevar de modo global o nível de escolaridade da população \\
\hline - melhorar a qualidade do ensino & - a melhoria da qualidade do ensino em todos os níveis \\
\hline
\end{tabular}

Fonte: Artigo 214 da Constituição federal e item 2, "Objetivos e Prioridades", do PNE.

Onde a sociedade brasileira indica, na Carta, programaticamente, há visível redução de ênfase no comando: erradicar o analfabetismo, como objetivo do plano, simplesmente desaparece. O legislador edulcora este fato grave (o descaso diante de uma das piores dívidas sociais, dentre tantas que as elites do país têm para com o povo) "explicando" que tal alvo estaria incluído na prioridade 2 reproduzida adiante (repetindo a surrada desculpa de que os "recursos financeiros são limitados"). No que poderia ser um esforço para contrabalançar tal rebaixamento, foram inseridas, na seção que trata da educação de jovens e adultos, metas indicando a tarefa de combate ao analfabetismo sem, no entanto, definir meios para concretizar aquele intento.

No mesmo sentido, a "universalização do atendimento escolar" foi transformada em "elevação global do nível de escolaridade da população", num visível rebaixamento de finalidades. É certo que se manteve o alvo da melhoria do ensino. Mas, como veremos, quando 
o PNE se viu na contingência de apontar os meios para torná-lo realidade - e isso certamente significa aumento de recursos - ou contornou o problema ou, se de alguma forma o enfrentou, o presidente da República vetou-o.

Os defensores do governo poderiam argüir que esse inaceitável rebaixamento, por intermédio de uma lei ordinária, dos objetivos fixados na Constituição seria atenuado no momento seguinte, quando o plano fixasse suas prioridades, que são reproduzidas na tabela adiante.

Não podemos esquecer que o Governo FHC demonstra total descompromisso com a efetivação dessas prioridades, mesmo rebaixadas. Na erradicação do analfabetismo, tem sido a prática contumaz desta administração relegar tal tarefa às ações de benemerência e às atividades associadas ao "Programa Comunidade Solidária". O presidente da República vetou, quando da sanção da Lei no 9.424/ 96, o dispositivo, inserido por consenso no parlamento, que incluía como gastos suscetíveis de serem cobertos pelas verbas do FUNDEF (Fundo de Manutenção e Desenvolvimento do Ensino Fundamental e de Valorização do Magistério) - aqueles voltados para manutenção e desenvolvimento do ensino de jovens e adultos.

Quanto às promessas de ampliar o atendimento melhorando a qualidade do ensino, basta que se mencione um fato objetivo para que se verifique a completa falta de sinceridade do atual governo federal. Ele rebaixa arbitrariamente o valor do "custo-mínimo-aluno/ano" para o repasse aos estados, que não alcançam o valor mínimo estabelecido pela legislação relativa aos FUNDEFs, o que prejudica irremediavelmente as crianças matriculadas nos estados mais pobres da federação. A propósito, levantamento feito pela assessoria da bancada federal do PT demonstrou que, com o referido rebaixamento, de 1997 a 2001, o governo federal, além de não repassar aos FUNDEFs algo equivalente a $\mathrm{R} \$ 8,150$ bilhões, deixou as crianças de seis estados sem acesso ao complemento determinado pela Emenda Constitucional no 14 e pela Lei no $9.424 / 96$ !

\section{A pressão social obriga à aprovação de elementos do Plano}

Graças à pressão social produzida, sobretudo, pelos profissionais da educação, o texto do PNE votado no parlamento contemplou algumas medidas - a esmagadora maioria delas seria vetada posteriormente, por FHC - que atenuavam os traços de simples "carta de intençôes”, que marcavam o texto da lei aprovada. O governo não 
conseguiu aprovar simplesmente um "não-plano", como revelavam suas intençóes e movimentos preliminares. $\mathrm{O}$ que deu ao projeto aprovado no parlamento uma leve conotação de plano efetivo incide de modo mais visível no tema "financiamento da educação". O governo, em seu projeto, assim como em suas ações concretas, trabalhava (como trabalha) com a lógica do ajuste estrutural imposto pelo FMI. Por isso, postula basicamente a manutenção do status quo. Ignorando a necessidade de ampliar o dispêndio público em educação, o Executivo fecha os olhos para a experiência de países que venceram o desafio educacional (eles investiram maciçamente - o Japão, por exemplo, gastou $14 \%$ do PIB, no imediato pós-guerra). Desconsidera, também, que, em termos concretos, nesse terreno, o nosso país, ainda nos anos de 1990, mantinha-se bastante atrás de outros de mesmo nível de desenvolvimento econômico. Em resumidas palavras, nesse ponto o relator e a bancada do governo não puderam sustentar a credibilidade dos números artificiosos apresentados pelo Executivo. Por isso, estabeleceram, como meta a ser atingida na década de validade do plano, a elevação para $7 \%$ do PIB no gasto público com educação.

\section{Propostas da sociedade versus PNE}

O texto legal aprovado evidencia a distância entre o que a sociedade postulava, por meio do PL no 4.155/98, e o que o Congresso aprovou. Para verificar isso, basta que comparemos apenas o definido como "Diretrizes Gerais" no PL no $4.155 / 98$ com os "Objetivos e Prioridades" (Item 2, da seção I - Introdução) do PNE aprovado.

\begin{tabular}{|c|c|}
\hline $\begin{array}{l}\text { PNE DA SOCIEDADE } \\
\text { DIRETRIZES GERAIS }\end{array}$ & $\begin{array}{l}\text { PNE APROVADO - ITEM 2, OBJETIVOS E } \\
\text { PRIORIDADES }\end{array}$ \\
\hline Consolidar um Sistema Nacional de Educação. & $\begin{array}{l}\text { Não trata do tema (em verdade opöe-se a esse instru- } \\
\text { mento). }\end{array}$ \\
\hline $\begin{array}{l}\text { Assegurar os recursos públicos necessários à supera- } \\
\text { ção do atraso educacional e ao pagamento da dívida } \\
\text { social, bem como à manutenção e ao desenvolvi- } \\
\text { mento da educaçáo escolar em todos os níveis e } \\
\text { modalidades, em todos os sistemas de educação. }\end{array}$ & $\begin{array}{l}\text { Redução das desigualdades sociais e regionais no } \\
\text { tocante ao acesso e à permanência, com sucesso, } \\
\text { na educaçáo pública. }\end{array}$ \\
\hline $\begin{array}{l}\text { Assegurar a autonomia das escolas e universida- } \\
\text { des na elaboração do projeto político-pedagógico } \\
\text { de acordo com as características e necessidades da } \\
\text { comunidade, com financiamento público e } \\
\text { gestão democrática, na perspectiva da consolida- } \\
\text { ção do Sistema Nacional de Educação. }\end{array}$ & \\
\hline
\end{tabular}


Universalizar a educação básica (nos seus diversos níveis e modalidades) e democratizar o ensino superior, ampliando as redes de instituiçóes educacionais, os recursos humanos devidamente qualificados e o número de vagas e fortalecendo o caráter público, gratuito e de qualidade da educaçáo brasileira, em todos os sistemas de educação.

Garantir a gestão democrática nos sistemas de educação nas instituições de ensino.
Garantia de ensino fundamental obrigatório de oito anos a todas as crianças de 7 a 14 anos, assegurando o seu ingresso e a permanência na escola e a conclusão desse ensino (...) Ampliação do atendimento nos demais níveis de ensino educação infantil, o ensino médio e a educação superior (...).

Democratização da gestão do ensino público, nos estabelecimentos oficiais, obedecendo aos princípios de participação dos profissionais da educação na elaboração do projeto pedagógico da escola e a participação das comunidades escolar e local em conselhos escolares ou equivalentes.

Garantir a valorização dos profissionais da educação (professores, técnicos e funcionários administrativos) em sua formação básica e continuada, carreira e salário.

Valorização dos profissionais da educação. Particular atenção deverá ser dada à formação inicial e continuada, em especial dos professores. Faz parte dessa valorização a garantia das condiçôes adequadas de trabalho, entre elas o tempo para estudo e preparação de aulas, salário digno, com piso salarial e carreira de magistério.

Garantir a educação pública, gratuita e de qualidade para crianças, jovens e adultos com necessidades educacionais especiais, aparelhando as unidades escolares, adequando-lhes os espaços, alocando-lhes recursos humanos suficientes e devidamente qualificados, em todos os sistemas públicos regulares de educação e em todos os níveis e modalidades de ensino.

Definir a erradicação do analfabetismo como política permanente - e não como conjunto de açóes pontuais, esporádicas, de caráter compensatório - utilizando, para tanto, todos os recursos disponíveis do Poder Público, das universidades, das entidades e organizaçóes da sociedade civil.

Garantir a organização de currículos que assegurem a identidade do povo brasileiro, o desenvolvimento da cidadania, as diversidades regionais, étnicas, culturais, articuladas pelo Sistema Nacional de Educação. Incluindo, nos currículos, temas específicos da história, da cultura, das manifestações artísticas, científicas, religiosas e de resistência da raça negra, dos povos indígenas, e dos trabalhadores rurais, e suas influências e contribuiçóes para a sociedade e a educação brasileiras.

Instituir mecanismos de avaliação interna e externa em todos os segmentos do Sistema Nacional de Educação, com a participação de todos os envolvidos no processo educacional, por meio de uma dinâmica democrática, legítima e transparente, que parte das condiçốes básicas para o desenvolvimento do trabalho educativo até chegar a resultados socialmente significativos.
Não trata do tema em nível de prioridade.

Garantia de ensino fundamental a todos os que a ele não tiveram acesso na idade própria ou que não o concluíram. A erradicação do analfabetismo faz parte dessa prioridade, considerando-se a educação de jovens e adultos como ponto de partida e parte intrínseca desse nível de ensino.

Não trata do tema em nível de prioridade.

Desenvolvimento de Sistemas de Informação e de avaliação em todos os níveis e modalidades de ensino, inclusive educação profissional, contemplando também o aperfeiçoamento dos processos de coleta e difusão dos dados, como instrumentos indispensáveis para a gestão do sistema educacional e melhoria do ensino. 
Em complemento a essas diretrizes indicadas acima, o II CONED inseriu, em sua proposta de PNE, metas que retomam reivindicações históricas dos movimentos sociais e explicitam o caráter democrático e popular de seu programa. Essas metas são as seguintes:

- Revogar imediatamente toda a legislação que impede ou fere a organização e o funcionamento democrático da educação brasileira (Lei no 9.192/95; Lei no 9.131/95; Lei no 9.3941 96; Emenda Constitucional no 14/96; Lei no 9.424/96; Decreto $n^{\circ}$ 2.208/97; entre outras).

- Instituir, no prazo de um ano, o Fórum Nacional de Educação como instância deliberativa da política educacional brasileira.

- Redefinir, imediatamente, o Conselho Nacional de Educação como órgão normativo e de coordenação do Sistema Nacional de Educação, bem como sua composição e funções.

- Redefinir, imediatamente, os Conselhos Estaduais e Municipais de Educação como órgãos normativos e coordenadores das politicas educacionais, nos níveis estaduais e municipais.

$\mathrm{O}$ que ressalta de todas essas comparaçôes é que o substitutivo Marchezan, aprovado no Congresso, consagra como "plano" a política educacional já praticada pelo MEC. Esse PNE significa a recusa de um verdadeiro Sistema Nacional de Educação. Em troca do sistema educacional, reafirmou-se, conferindo-lhe o estatuto de lei, o Sistema Nacional de Avaliação - instrumento nuclear do excessivo centralismo na gestão da educação nacional. O PNE aprovado não viabiliza mecanismos de gestão democrática do ensino. Além de reduzir a democracia à "participação da comunidade escolar e da sociedade" na implementação prática de deliberações definidas na cúpula do Estado, esta é entendida como algo de economia exclusiva do ensino público.

Essa doutrina, portanto, é oposta ao postulado no PNE da Sociedade Brasileira, que reivindica uma escola pública, gratuita, democrática e de exigente padrão qualitativo para todos, a serviço de um projeto de país voltado para o povo brasileiro. O que requer, entre outros compromissos: a) aumentar substantivamente o gasto público; b) universalizar a educação básica, ampliar e democratizar o ensino superior público; c) implementar um Sistema Nacional de Educação; d) gestão efetivamente democrática da educação; garantia de educação pública, gratuita para os portadores de necessidades educacionais especiais; erradicação do analfabetismo como política 
permanente etc. Um desdobramento lógico e necessário para implementar essas demandas seria a revogação das leis que sustentam a atual política educacional.

Os vetos de FHC fazem do PNE uma carta de intenções

Os vetos impostos ao que foi aprovado no parlamento ilustram o caráter inócuo que a atual administração federal atribui ao PNE. $\mathrm{Na}$ mensagem $\mathrm{n}^{\circ}$ 9, de 9/1/2001, na qual comunica os vetos ao parlamento, o presidente da República confessa que sua posição ante a matéria foi ditada pela área econômica do governo e não pelos seus auxiliares e organismos diretamente responsáveis pela educação. As razões da política ditada pelo FMI determinaram, na verdade, a decisão presidencial e não quaisquer considerações de ordem "interna".

Foram nove os vetos ao que foi aprovado pelo Legislativo. O primeiro referia-se à educação infantil na meta que determinava a ampliação do programa de renda mínima. Os quatro outros seguintes incidiram sobre o ensino superior, especificamente na meta que determinava que o número de vagas no ensino superior público não poderia ser inferior a $40 \%$ do total deste nível de ensino; na que subvinculava $75 \%$ dos recursos da União voltados para manutenção e desenvolvimento do ensino à manutenção e expansão da rede federal de ensino superior; na que determinava a ampliação do programa de crédito educativo a 30\% dos alunos da rede privada; e na que determinava a implantação de planos gerais de carreira para os funcionários das universidades federais. Outro veto incidiu sobre a meta que mandava ampliar o financiamento público à pesquisa científica e tecnológica.

Dois outros vetos diziam respeito, precisamente, ao financiamento público da educação. O principal item vetado tem a seguinte redação: "elevação, na década, através do esforço conjunto da União, estados, Distrito Federal e municípios, do percentual de gastos públicos em relação ao PIB, aplicados em educação, para atingir o mínimo de $7 \%$. Para tanto, os recursos devem ser ampliados, anualmente, à razão de $0,5 \%$ do PIB, nos quatro primeiros anos do Plano e de $0,6 \%$ no quinto ano". O outro veto é igualmente curioso: manda que as três esferas do Poder Público, ao elaborarem os orçamentos, respeitem as vinculaçôes e subvinculaçôes constitucionais relativas à educação, bem como os valores necessários à garantia de minimos padróes de qualidade do ensino. $O$ último veto incidiu sobre o dispositivo que determinava que o pagamento 
dos aposentados e pensionistas do ensino superior público deveria ser excluido das despesas consideradas como manutenção e desenvolvimento do ensino.

O presidente vetou tudo que pudesse ter a imagem de um plano. Este deve sempre ser dotado de verbas para viabilizar as diretrizes e metas propostas. Sintomaticamente, nenhum veto decorre do fato de que o governo tenha um ponto de vista pedagógico diferente do contido no dispositivo vetado. $\mathrm{O}$ que determinou a atitude presidencial foi a doutrina que afirma serem os gastos sociais (salvo aqueles, em geral de caráter compensatório, contemplados na execução do ajuste estrutural) algo estranho e hostil à política do FMI. Essa política, como se sabe, já está interiorizada nas contra-reformas do governo, em várias emendas constitucionais já aprovadas e nas leis. O paradigma mais completo disso é a dita "Lei de Responsabilidade Fiscal". Não por acaso, é nela que FHC se louva para justificar todos os vetos.

\section{Considerações finais}

O PNE aprovado pelo Congresso, assim como a LDB e a legislação educacional, aprovadas sob a égide do pacto conservador que atualmente controla o governo brasileiro, traduzem a compreensão de que a política educacional deve ser concebida e praticada hostilizando-se o pensamento, as reivindicaçóes, os anseios da comunidade escolar. Mais do que isso, essa orientação materializa no Brasil a política do Banco Mundial para os países subdesenvolvidos.

Neste sentido e até por isso, o PNE, como lei, de conjunto não contempla as propostas e reivindicaçóes dos setores democráticos e populares da sociedade. Ele é uma espécie de salvo-conduto para que o governo continue implementando a política que já vinha praticando. Vimos, também, que, como foi aprovado no parlamento, este PNE já estava claramente comprometido, em sua validade, pelo traço de carta de intençôes. Os vetos que FHC impôs à lei, além de radicalizarem tal característica, retiraram do PNE precisamente alguns dispositivos que a pressão popular havia forçado a que fossem inseridos.

Assim é que já se desenvolvem diversas formas de pressão social sobre o parlamento, a fim de induzi-lo a respeitar o que ele mesmo delibera e a derrubar os vetos presidenciais. É certo que os setores democráticos e populares, ao apresentarem seu projeto de PNE ao Congresso, não nutriam vãs esperanças de que, sob o atual esquema de poder, pudessem ver suas reivindicaçôes e propostas aprovadas. 
O mais importante é que elas persistem como um guia indispensável para todos os que querem lutar contra o neoliberalismo na educação, no interior das escolas, nas ruas ou no Estado. É fundamental prosseguir a luta em favor de um verdadeiro PNE, ligado à sociedade brasileira, nas disputas em torno dos Planos Estaduais e Municipais de Educação, bem como na organização das reivindicações educacionais do povo e das demandas dos profissionais da educação. A articulação dos movimentos sociais, o conhecimento detalhado da realidade e a disputa global de propostas e projetos parecem ser o caminho mais profícuo para a continuidade da luta por uma escola pública, gratuita, democrática e de qualidade social para todos, no Brasil.

Recebido e aprovado em julho de 2002.

Referências bibliográficas

BRASIL. Lei 10.172 , de 9 de janeiro de 2001. Aprova o Plano Nacional de Educação e dá outras providencias. Diário Oficial da União. Brasília, DF, 10 jan. 2001.

MENSAGEM n. 9, de 9 de janeiro de 2001. Diário Oficial da Uniāo. Brasília, DF, 10 jan. 2001.

VALENTE, I.; ROMANO, R. O plano vetado em nome do ajuste fiscal. Folha de S. Paulo. São Paulo, p. 3, 4 abr. 2001.

VAlENTE, I. Para um balanço do PNE. In: Plano Nacional de Educação. Rio de Janeiro: DP\&A, 2001. p. 9-44. 